What then of the changes. "If it ain't

\title{
New year, new editorial team
}

\section{N Rossor, M G Hanna}

$\mathrm{T}$ he New Year brings a change of editorship; after seven years of exceptional custodianship the journal says goodbye to Professor Chris Kennard. During his tenure he has maintained the key role of the journal as a premier European clinical neuroscience publication and witnessed an increase in submissions from about 1200 to over 2000 per annum. He has established online submissions via Bench $>$ Press and established the website. He has overseen the introduction of Neurology in Practice, edited by Ian Bone and Geraint Fuller, which will continue in this series until 2005. A number of new features have been introduced, such as editorial commentaries. All of these provide added value to the quality of the submitted articles. It is this added value which is of such importance during the time of the information explosion and online publishing opportunities. These opportunities are indeed substantial, both to increase the amount of information available but also to distribute journals to a wider audience at ever lower marginal cost. The danger, however, is that as quantity increases quality falls. Chris Kennard has met these challenges and hands over the journal in excellent shape.

\section{THE FUTURE}

What of the future? JNNP was first published in 1938 (under the title of Journal of Neurology and Psychiatry) and the custodianship of such a journal is both an exciting challenge and a heavy responsibility. We reaffirm the aim of publishing the very best articles of clinical relevance in neurology, neurosurgery, and psychiatry. There are few clinical neuroscience journals that are as broadly based and it would be easy to focus just on neurology. However, we believe that this multidisciplinary nature is its strength, and indeed we hope to foster increased submissions in neurosurgery and psychiatry. broke don't mend it"; and so with a successful journal, changes in response to changing demands should occur with minimal fuss. We hope to raise the international profile of the journal and to this end there will be changes in the balance of the editorial team and details of this will follow in future issues. As always, we depend very much on the generosity and support, not only of the editorial board, but also of the large number of referees who assist with maintaining the quality of the journal. With increasing pressure of time and the increasing submission rate, this becomes ever more onerous, but without such freely given scholarship the journal cannot survive.

There is one change that is already apparent, namely the cover. We felt it was time for a change and the new cover highlights the three clinical subjects of neurology, neurosurgery, and psychiatry. The picture will change each month but what has not changed is the colour; JNNP remains "the green rag".

J Neurol Neurosurg Psychiatry 2004;75:

\section{Authors' affiliations}

Martin N Rossor, Michael G Hanna, Institute of Neurology, Queen Square, London WCIN 3BG, UK

Correspondence to: Professor Martin Rossor mrossor@dementia.ion.ucl.ac.uk

\section{Contribution of cerebral amyloid angiopathy to Alzheimer's disease}

\section{S Love}

\section{Contribution of CAA to Alzheimer's disease}

I: patients with Alzheimer's disease $(A D)$, focal and diffuse ischaemic abnormalities of the cerebral white matter can be demonstrated neuropathologically ${ }^{1-3}$ and neuroradiologically. ${ }^{4-8}$ The focal lesions have been shown to contribute to motor and neuropsychiatric manifestations of $\mathrm{AD},{ }^{9-12}$ and the more widespread or diffuse abnormalities to impaired cognition. ${ }^{13}{ }^{14}$ In some series, ischaemic cerebral lesions in $\mathrm{AD}$ have been more frequent in patients homozygous or heterozygous for the epsilon 4 (e4) allele of the apolipoprotein E gene $(A P O E),{ }^{15-17}$ but other studies have found no such association, ${ }^{18-21}$ Studies of the relation between white matter disease in patients with $\mathrm{AD}$ or probable $\mathrm{AD}$, and the systemic manifestations of arteriosclerotic vascular disease, have yielded inconsistent findings. ${ }^{11}$ 21-24

Several observations implicate cerebral amyloid angiopathy (CAA) as the probable cause of much of the white matter damage in $\mathrm{AD}$. The vascular deposition of amyloid $\beta$ protein $(A \beta)$ is much more frequent and tends to be much more severe in patients with $\mathrm{AD}$ than in age-matched controls. ${ }^{25-29}$
Furthermore, CAA is a well documented risk factor for cerebral infarction ${ }^{16}$ 30-32 $^{3}$ and for focal and diffuse white matter ischaemic lesions. ${ }^{33-36}$ The mechanisms whereby CAA may cause ischaemic damage to the white matter probably include a combination of luminal stenosis, endothelial damage, basement membrane thickening, thrombosis, loss of autoregulation, and vasospasm. ${ }^{37-40}$ Because evidence of the involvement of CAA in $\mathrm{AD}$ is largely based on postmortem studies, which are by their nature skewed towards end stage disease, it could be argued that any contribution of CAA may be confined to the terminal stages of disease. If this were true, it might be expected that an inverse relationship between the severity of CAA at autopsy and the duration of $\mathrm{AD}$ would be found. That this is not the case $^{28}$ suggests that CAA may exacerbate $\mathrm{AD}$ even at an early stage.

The occurrence of CAA in $\mathrm{AD}$ is strongly associated with possession of the e4 allele of $A P O E .^{17} 283241$ Indeed, possession of the e4 allele of APOE is much more strongly correlated with vascular than parenchymal deposition 


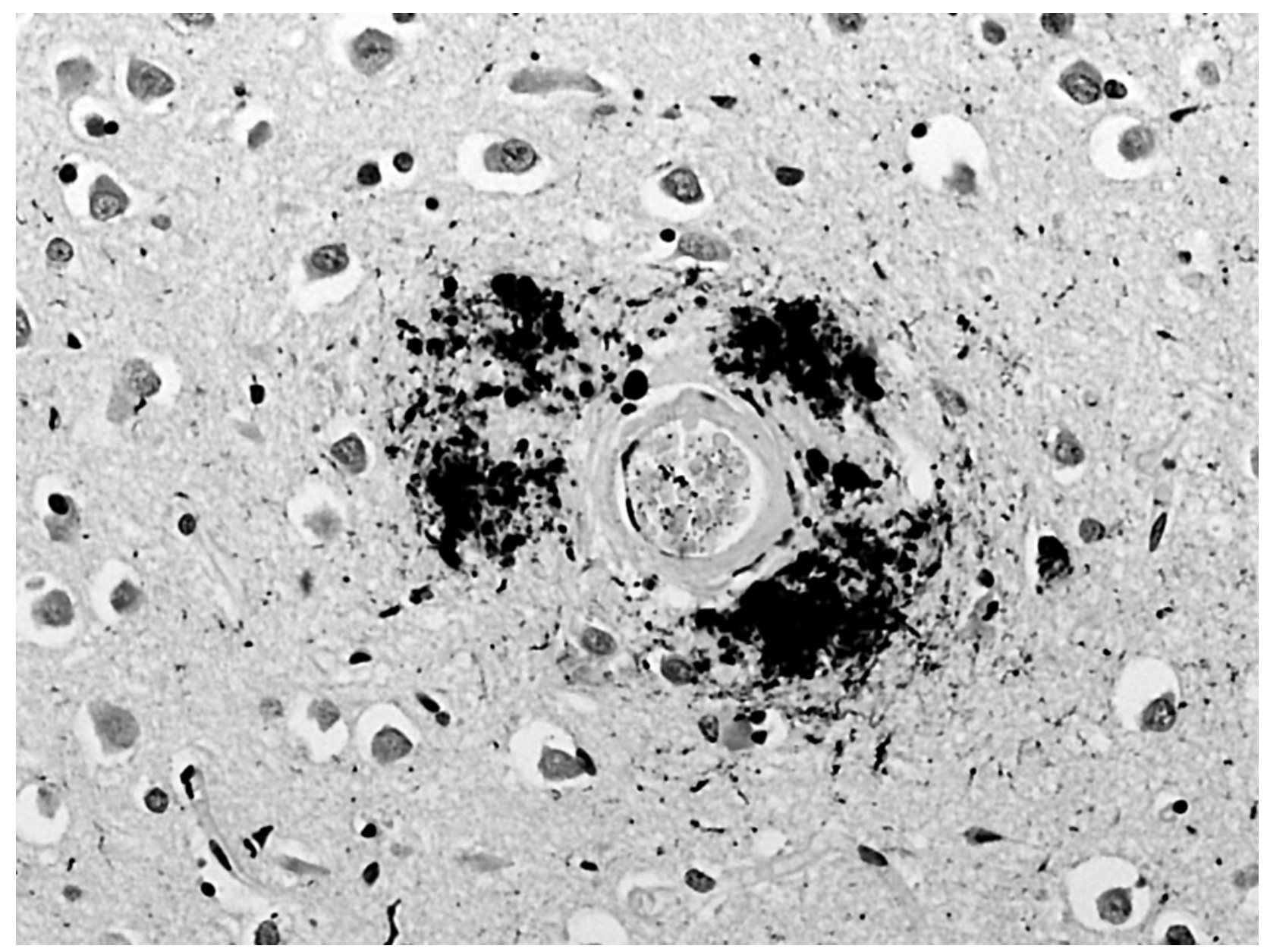

Figure 1 Tau immunopositive neurites clustered around a cortical artery with dyshoric amyloid angiopathy.

of $\mathrm{A} \beta .^{28}$ This may reflect on the pathogenesis of neurodegeneration in $\mathrm{AD}$ in patients with e4. AD patients with severe CAA, almost all of whom possess at least one e4 allele, have significantly less parenchymal $A \beta$ than do patients with lesser degrees of CAA..$^{28}{ }^{42} 43$ This is further evidence against the argument that CAA is simply a late manifestation of $\mathrm{AD}$, and raises the possibility that $\mathrm{CAA}$ and parenchymal $\mathrm{A} \beta$ have additive effects on the progression of clinical disease. Although the $A \beta$ within vessel walls could, in theory, also cause local neurotoxicity in the cerebral cortex, we have found no evidence of any associated reduction in the density of immunostaining of synaptophysin, ${ }^{44}$ a sensitive marker of presynaptic integrity.

Observations of Weller and colleagues suggest that the involvement of CAA in $\mathrm{AD}$ may go beyond a contribution of ischaemia to the clinical and pathological manifestations of the disease, and that CAA may be involved in the development of plaques and tangles, the histological hallmarks of $\mathrm{AD}$. Weller et $a l^{45}{ }^{46}$ propose that soluble $A \beta$ is normally eliminated from the brain within interstitial fluid pathways that reach the cerebrospinal fluid in the subarachnoid space by passing along perivascular spaces in the cerebral cortex. If this model is correct, the obstruction to drainage of interstitial fluid caused by perivascular accumulation of amyloid could contribute to the accumulation of $\mathrm{A} \beta$ within the parenchyma and the development of the plaques and tangles. Support for this comes from the occasional finding of tau immunopositive neurites clustered around larger arteries with dyshoric amyloid angiopathy (angiopathy in which amyloid extends from the affected blood vessels into the surrounding brain parenchyma) (fig 1). Although the flow of interstitial fluid within the perivascular space occurs in the opposite direction to that of the arterial blood flow, it may be enhanced by the pulsatile arterial distension. A failure of this propulsive mechanism has been proposed to explain the association of capillary CAA with thrombosis of overlying cortical arteries. ${ }^{4}$

However, several other observations indicate that the relationship between
CAA, plaques, and tangles is more complicated than would be predicted by a simple model of obstruction to drainage. These include the mutually exclusive topographical relationship between capillary CAA and extensive diffuse plaques, ${ }^{47}$ and the inverse correlation between overall severity of amyloid angiopathy and parenchymal amyloid load in patients with moderate to severe CAA. ${ }^{28} 4345$ Further evidence suggests that soluble $A \beta$ within the brain is largely cleared by lipoprotein receptor related protein-1 mediated transcytosis across the endothelial cells of the blood-brain barrier. ${ }^{48}$ Impaired clearance of $A \beta$ across the blood-brain barrier is probably central to the development of CAA in hereditary cerebrovascular amyloidosis with Dutch type haemorrhage ${ }^{49}$ caused by a $\mathrm{G} \rightarrow \mathrm{C}$ transition at codon 693 of the $\beta$ amyloid precursor protein gene.

Studies by Wyss-Coray et $a l^{43} 5051$ identify transforming growth factor $\beta$ (TGF $\beta$ ) as a key influence on the relationship between parenchymal and vascular $A \beta$ in $A D$. TGF $\beta 1$ levels are significantly increased in patients with 
$\mathrm{AD}$, not only in the cerebral cortex, ${ }^{52}$ but also in the serum and CSF. ${ }^{53}{ }^{54}$ Chao et $a l^{53}$ observed a significant in vivo correlation between the level of TGF $\beta 1$ in the serum and the severity of dementia. On the face of it, this might seem paradoxical, as TGF $\beta 1$ has been shown to promote the clearance of $A \beta$ from the parenchyma of transgenic mice expressing human $\beta$ amyloid precursor protein. ${ }^{43}$ However, in contrast to the beneficial effects of TGF $\beta 1$ on clearance of parenchymal amyloid, expression of TGF $\beta 1$ by astrocytes in transgenic mice actually induces deposition of amyloid in cerebral blood vessels, this being accelerated by co-expression of human $\beta$ amyloid precursor protein. ${ }^{50}{ }^{51}$ A parallel can be drawn between the latter finding and the detection of severe CAA in regions of brain with markedly reduced parenchymal $A \beta$ in a patient with $\mathrm{AD}$ who was immunized with $\mathrm{A} \beta$ (peptide fragment AN-1792)..$^{55}$ The relevance of the observations of Wyss-Coray et al to $\mathrm{AD}$ was strengthened by the authors' demonstration of a strong correlation between TGF $\beta 1$ mRNA levels and the severity of CAA in post-mortem brain tissue from 15 patients with $A D$ and 7 controls. $^{51}$ However, while these post-mortem findings are of interest, it should be noted that the number of cases studied was small.

Many questions remain as to the relation between CAA and AD. Apart from e4, the putative genetic risk factors for CAA show relatively little overlap with those for $\mathrm{AD}^{56}{ }^{57}$ and despite the fact that e4 is a major risk factor for $\mathrm{CAA}$ in $\mathrm{AD}$ and in patients presenting with cerebral haemorrhage, CAA is probably not associated with the $A P O E$ genotype if these conditions are excluded. ${ }^{29}$ Although CAA is present in over $90 \%$ of patients with $\mathrm{AD}$, it is not present in all cases and is therefore clearly not necessary for the development of the disease. Indeed, it is becoming increasingly clear that what we refer to as $\mathrm{AD}$ is really a spectrum of disorders with different genetic (and probably environmental) risk factors but having overlapping pathological and clinical phenotypes. For example, e4 associated $\mathrm{AD}$ tends to be a disease with moderate to severe CAA, AD caused by some presenilin mutations is characterized by cotton wool plaques and pyramidal tract degeneration, ${ }^{58-63}$ and $\mathrm{AD}$ in patients with an e2 APOE allele and CAA carries an increased risk of parenchymal brain haemorrhage..$^{64} 65$

The accurate diagnosis of CAA is likely to become increasingly important as we evaluate and implement treatments such as immunization, which are aimed at clearing parenchymal $A \beta$ in $\mathrm{AD}$, particularly if these carry a risk of promoting vascular deposition of $\mathrm{A} \beta .^{55}$ However, the ante-mortem diagnosis of $\mathrm{CAA}$ in $\mathrm{AD}$ remains a challenge. Measurement of plasma levels of $A \beta$ and TGF $\beta$ was found to be unhelpful in predicting CAA. ${ }^{66}$ For the time being, except in the relatively few patients who manifest with lobar cerebral haemorrhage $^{67}$ or have a brain biopsy, ${ }^{68}{ }^{69}$ we will have to continue to rely on examination of the brain at autopsy to make a confident diagnosis of CAA.

J Neurol Neurosurg Psychiatry 2004;75:1-4

Correspondence to: $\operatorname{Dr} S$ Love, Department of Neuropathology, Institute of Clinical Neurosciences, Frenchay Hospital, Bristol BS16 $1 \mathrm{LE}$, UK; seth.love@bris.ac.uk

\section{REFERENCES}

1 Brun A, Englund E. A white matter disorder in dementia of the Alzheimer type: a pathoanatomical study. Ann Neurol 1986; 19:253-62

2 Scheltens P, Barkhof F, Leys D, et al. Histopathologic correlates of white matter changes on MRI in Alzheimer's disease and normal aging. Neurology 1995;45:883-8.

3 Tomimoto $\mathrm{H}$, Akiguchi I, Akiyama $\mathrm{H}$, et al. Vascular changes in white matter lesions of Alzheimer's disease. Acta Neuropathol 1999;97:629-34.

4 Catani M, Cherubini A, Howard R, et al. (1)H-MR spectroscopy differentiates mild cognitive impairment from normal brain aging Neuroreport 2001;12:2315-17.

5 De Stefano N, Mortilla M, Federico A. Proton magnetic resonance spectroscopy of the brain in dementia. Ital J Neurol Sci 1999;20:S258-64.

6 DeCarli C, Grady CL, Clark CM, et al. Comparison of positron emission tomography, cognition, and brain volume in Alzheimer's disease with and without severe abnormalities of white matter. I Neurol Neurosurg Psychiatry 1996;60: 158-67

7 Hanyu $H$, Sakurai $H$, Iwamoto $T$, et al. Diffusionweighted MR imaging of the hippocampus and temporal white matter in Alzheimer's disease. J Neurol Sci 1998;156:195-200.

8 Rose SE, Chen F, Chalk JB, et al. Loss of connectivity in Alzheimer's disease: an evaluation of white matter tract integrity with colour coded MR diffusion tensor imaging. J Neurol Neurosurg Psychiatry 2000;69:528-30.

9 Bennett DA, Gilley DW, Wilson RS, et al. Clinical correlates of high signal lesions on magnetic resonance imaging in Alzheimer's disease. J Neurol 1992;239:186-90.

10 Bennett DA, Gilley DW, Lee S, et al. White matter changes: neurobehavioral manifestations of Binswanger's disease and clinical correlates in Alzheimer's disease. Dementia 1994;5:148-52.

11 Hirono N, Kitagaki H, Kazui H, et al. Impact of white matter changes on clinical manifestation of Alzheimer's disease: A quantitative study. Stroke 2000;31:2182-8

12 O'Brien J, Perry R, Barber R, et al. The association between white matter lesions on magnetic resonance imaging and noncognitive symptoms. Ann NY Acad Sci 2000;903:482-9.

13 Parnetti L, Tarducci R, Presciutti O, et al. Proton magnetic resonance spectroscopy can differentiate Alzheimer's disease from normal aging. Mech Ageing Dev 1997;97:9-14.

14 Amar K, Bucks RS, Lewis T, et al. The effect of white matter low attenuation on cognitive performance in dementia of the Alzheimer type. Age Ageing 1996;25:443-8

15 Bronge L, Fernaeus SE, Blomberg $M$, et al. White matter lesions in Alzheimer patients are influenced by apolipoprotein E genotype. Dement Geriatr Cogn Dis 1999;10:89-96.

16 Olichney JM, Hansen LA, Lee JH, et al. Relationship between severe amyloid angiopathy, apolipoprotein E genotype, and vascular lesions in Alzheimer's disease. Ann NY Acad Sci 2000;903:138-43.

17 Premkumar DR, Cohen DL, Hedera $\mathrm{P}$, et al. Apolipoprotein $\mathrm{E}-\varepsilon 4$ alleles in cerebral amyloid angiopathy and cerebrovascular pathology associated with Alzheimer's disease. Am J Pathol 1996; 148:2083-95

18 Barber R, Gholkar A, Scheltens $P$, et al. Apolipoprotein E \&4 allele, temporal lobe atrophy, and white matter lesions in late-life dementias. Arch Neurol 1999;56:961-5.

19 Doody RS, Azher SN, Haykal HA, et al. Does $\mathrm{APO} \& 4$ correlate with MRI changes in Alzheimer's disease? J Neurol Neurosurg Psychiatry 2000;69:668-71.

20 Hirono N, Yasuda M, Tanimukai S, et al. Effect of the apolipoprotein E epsilon4 allele on white matter hyperintensities in dementia. Stroke 2000;31:1263-8.

21 Sawada H, Udaka F, Izumi Y, et al. Cerebral white matter lesions are not associated with apoE genotype but with age and female sex in Alzheimer's disease. J Neurol Neurosurg Psychiatry 2000;68:653-6.

22 Kawamura J, Meyer JS, Terayama Y, et al. Cerebral white matter perfusion in dementia of Alzheimer type. Alz Dis Assoc Dis 1991;5:231-9.

23 Lopez OL, Becker JT, Rezek D, et al. Neuropsychiatric correlates of cerebral whitematter radiolucencies in probable Alzheimer's disease. Arch Neurol 1992;49:828-34.

24 Blennow K, Wallin A, Uhlemann C, et al. Whitematter lesions on $\mathrm{CT}$ in Alzheimer patients: relation to clinical symptomatology and vascular factors. Acta Neurol Scand 1991;83:187-93.

25 Yamada M, Tsukagoshi $\mathrm{H}$, Otomo $\mathrm{E}$, et al. Cerebral amyloid angiopathy in the aged. J Neurol 1987:234:371-6.

26 Vinters HV, Gilbert JJ. Cerebral amyloid angiopathy: incidence and complications in the aging brain. II. The distribution of amyloid vascular changes. Stroke 1983;14:924-8.

27 Esiri MM, Wilcock GK. Cerebral amyloid angiopathy in dementia and old age. J Neurol Neurosurg Psychiatry 1986;49:1221-6.

28 Chalmers K, Wilcock GK, Love S. APOE \&4 influences the pathological phenotype of Alzheimer's disease by favouring cerebrovascular over parenchymal accumulation of A $\beta$ protein. Neuropathol Appl Neurobiol 2003;29:231-8

29 Love S, Nicoll JA, Wilcock GK. APOE and cerebral amyloid angiopathy in the elderly. Neuroreport 2003; 14:1535-6.

30 Cadavid D, Mena H, Koeller K, et al. Cerebral $\beta$ amyloid angiopathy is a risk factor for cerebral ischemic infarction. A case control study in human brain biopsies. J Neuropathol Exp Neurol 2000;59:768-73.

31 Ellis RJ, Olichney JM, Thal $\sqcup$, et al. Cerebral amyloid angiopathy in the brains of patients with Alzheimer's disease: the CERAD experience, Part XV. Neurology 1996;46:1592-6.

32 Olichney JM, Hansen LA, Hofstetter CR, et al. Association between severe cerebral amyloid angiopathy and cerebrovascular lesions in Alzheimer disease is not a spurious one attributable to apolipoprotein E4. Arch Neurol 2000;57:869-74.

33 Gray F, Dubas F, Roullet E, et al. Leukoencephalopathy in diffuse hemorrhagic cerebral amyloid angiopathy. Ann Neurol 1985; 18:54-9.

34 Loes DJ, Biller J, Yuh WT, et al. Leukoencephalopathy in cerebral amyloid angiopathy: $M R$ imaging in four cases. Am J Neuroradiol 1990;11:485-8.

35 Yoshimura M, Yamanouchi $\mathrm{H}$, Kuzuhara S, et al. Dementia in cerebral amyloid angiopathy: a clinicopathological study. J Neurol 1992;239:441-50.

36 Haglund $M$, Englund E. Cerebral amyloid angiopathy, white matter lesions and Alzheimer encephalopathy - a histopathological assessment. Dement Geriatr Cogn Disord 2002;14:161-6.

37 Crawford F, Suo Z, Fang C, et al. Characteristics of the in vitro vasoactivity of $\beta$-amyloid peptides. Exp Neurol 1998;150:159-68.

38 Paris D, Town T, Parker TA, et al. Isoform-specific vasoconstriction induced by apolipoprotein $\mathrm{E}$ and 
modulation of this effect by Alzheimer's $\beta$ amyloid peptide. Neurosci Lett 1998;256:73-6.

39 de Figueiredo RJ, Oten R, Su J, et al. Amyloid deposition in cerebrovascular angiopathy. Ann NY Acad Sci 1997:826:463-71.

40 Kalaria RN. The blood-brain barrier and cerebrovascular pathology in Alzheimer's disease. Ann NY Acad Sci 1999;893:113-25.

41 Berg L, McKeel DW Jr, Miller JP, et al. Clinicopathologic studies in cognitively healthy aging and Alzheimer's disease: relation of histologic markers to dementia severity, age, sex and apolipoprotein E genotype. Arch Neurol 1998:55:326-35.

42 Weller RO, Massey A, Kuo YM, et al. Cerebral amyloid angiopathy: accumulation of $A \beta$ in interstitial fluid drainage pathways in Alzheimer's disease. Ann NY Acad Sci 2000;903:110-7.

43 Wyss-Coray T, Lin C, Yan F, et al. TGF- $\beta 1$ promotes microglial amyloid- $\beta$ clearance and reduces plaque burden in transgenic mice. Nat Med 2001;7:612-18.

44 Chalmers K, Wilcock GK, Love S. Cerebral amyloid angiopathy in Alzheimer's disease does not influence neocortical synaptic density or subcortical white matter accumulation of $\beta$ amyloid precursor protein. Neuropathol Appl Neurobiol 2003;29:184

45 Weller RO, Massey A, Newman TA, et al. Cerebral amyloid angiopathy: amyloid $\beta$ accumulates in putative interstitial fluid drainage pathways in Alzheimer's disease. Am J Pathol 1998; 153:725-33.

46 Preston SD, Steart PV, Wilkinson A, et al. Capillary and arterial cerebral amyloid angiopathy in Alzheimer's disease: defining the perivascular route for the elimination of amyloid $\beta$ from the human brain. Neuropathol Appl Neurobiol 2003;29:106-17.

47 Weller RO, Yow HY, Preston SD, et al. Cerebrovascular disease is a major factor in the failure of elimination of $A \beta$ from the aging human brain: implications for therapy of Alzheimer's disease. Ann NY Acad Sci 2002;977:162-8.
48 Shibata M, Yamada S, Kumar SR, et al. Clearance of Alzheimer's amyloid-ss(1-40) peptide from brain by LDL receptor-related protein-1 at the blood-brain barrier. J Clin Invest 2000; 106: 1489-99.

49 Monro OR, Mackic JB, Yamada S, et al Substitution at codon 22 reduces clearance of Alzheimer's amyloid- $\beta$ peptide from the cerebrospinal fluid and prevents its transport from the central nervous system into blood. Neurobiol Aging 2002;23:405-12.

50 Wyss-Coray T, Lin C, Sanan DA, et al. Chronic overproduction of transforming growth factor- $\beta 1$ by astrocytes promotes Alzheimer's disease-like microvascular degeneration in transgenic mice. Am J Pathol 2000;156:139-50.

51 Wyss-Coray T, Masliah E, Mallory M, et al. Amyloidogenic role of cytokine TGF- $\beta 1$ in transgenic mice and in Alzheimer's disease. Nature 1997;389:603-6.

52 Luterman JD, Haroutunian V, Yemul S, et al. Cytokine gene expression as a function of the clinical progression of Alzheimer disease dementia. Arch Neurol 2000;57:1153-60.

53 Chao CC, Ala TA, Hu S et al. Serum cytokine levels in patients with Alzheimer's disease. Clin Diagn Lab Immunol 1994; 1:433-6.

54 Chao CC, Hu S, Frey WH 2nd, et al. Transforming growth factor $\beta$ in Alzheimer's disease. Clin Diagn Lab Immunol 1994;1:109-10.

55 Nicoll JA, Wilkinson D, Holmes C, et al. Neuropathology of human Alzheimer disease after immunization with amyloid- $\beta$ peptide: a case report. Nat Med 2003:9:448-52.

56 Yamada M. Risk factors for cerebral amyloid angiopathy in the elderly. Ann NY Acad Sci 2002; 977:37-44

57 Yamada M, Sodeyama N, Itoh Y, et al. Association of neprilysin polymorphism with cerebral amyloid angiopathy. J Neurol Neurosurg Psychiatry 2003;74:749-51

58 Brooks WS, Kwok JB, Kril JJ, et al. Alzheimer's disease with spastic paraparesis and 'cotton wool' plaques: two pedigrees with PS-1 exon 9 deletions. Brain 2003;126:783-91.
59 Tabira $\mathrm{T}$, Chui de $\mathrm{H}$, Nakayama $\mathrm{H}$, et al. Alzheimer's disease with spastic paresis and cotton wool type plaques. J Neurosci Res 2002;70:367-72

60 Steiner H, Revesz T, Neumann M, et al. A pathogenic presenilin-1 deletion causes abberrant $A \beta 42$ production in the absence of congophilic amyloid plaques. $J \mathrm{Biol}$ Chem 2001;276:7233-9.

61 O'Riordan S, McMonagle P, Janssen JC, et al. Presenilin-1 mutation (E280G), spastic paraparesis, and cranial MRI white-matter abnormalities. Neurology 2002;59:1 108-10.

62 Verkkoniemi A, Kalimo H, Paetau A, et al. Variant Alzheimer disease with spastic paraparesis: neuropathological phenotype. J Neuropathol Exp Neurol 2001;60:483-92.

63 Houlden H, Baker M, McGowan E, et al. Variant Alzheimer's disease with spastic paraparesis and cotton wool plaques is caused by PS- 1 mutations that lead to exceptionally high amyloid- $\beta$ concentrations. Ann Neurol 2000;48:806-8.

64 Nicoll JA, Burnett C, Love S, et al. High frequency of apolipoprotein $\mathrm{E} \varepsilon 2$ allele in hemorrhage due to cerebral amyloid angiopathy. Ann Neurol 1997;41:716-21

65 McCarron MO, Nicoll JA. Apolipoprotein E genotype and cerebral amyloid angiopathyrelated hemorrhage. Ann NY Acad Sci 2000;903:176-9

66 Greenberg SM, Cho HS, O'Donnell HC, et al. Plasma $\beta$-amyloid peptide, transforming growth factor- $\beta 1$, and risk for cerebral amyloid angiopathy. Ann NY Acad Sci 2000;903:144-9.

67 Knudsen KA, Rosand J, Karluk D, et al. Clinical diagnosis of cerebral amyloid angiopathy: validation of the Boston criteria. Neurology 2001;56:537-9.

68 Greenberg SM, Vonsattel JP. Diagnosis of cerebral amyloid angiopathy. Sensitivity and specificity of cortical biopsy. Stroke 1997:28:1418-22.

69 McCarron MO, Nicoll JA, Love S, et al. Surgical intervention, biopsy and APOE genotype in cerebral amyloid angiopathy-related haemorrhage. Br J Neurosurg 1999;13:462-7. symptoms and cerebrovascular events, although minimal attention has been paid to defining the dementia in vascular dementia. Similar to clinical features used to define Alzheimer's disease dementia, the clinical symptoms required for the identification of dementia in vascular dementia frequently emphasise memory impairment as the primary criterion. However, despite the limitations of previous research due to the lack of uniform diagnostic criteria, as well as the individual variability associated with cerebrovascular disease, the most consistent finding that has emerged regarding the neuropsychological profile in vascular dementia has been the relative preservation of memory functioning as compared with subjects with Alzheimer's disease. ${ }^{5}$ This finding, as well as other characteristic neuropsychological impairments as described in the current study, may eventually lead to an improvement in the ability to accurately diagnose vascular dementia in the clinical setting. Continued research is needed in this area, including clinicopathological studies, to further refine the clinical 
profile in vascular dementia and improve the specificity of diagnostic criteria.

J Neurol Neurosurg Psychiatry 2004;75:4-5

Correspondence to: N A Johnson, Cognitive Neurology \& Alzheimer's Disease Center, Northwestern University Medical School, 320 East Superior Street, Suite 11-499, Chicago, IL 60611, USA; johnson-n@northwestern.edu

\section{REFERENCES}

1 Graham NL, Emery T, Hodges JR. Distinctive cognitive profiles in Alzheimer's disease and subcortical vascular dementia. J Neurol Neurosurg Psychiatry 2003;74:61-71.

2 Roman GC, Tatemichi TK, Erkinjuntti T, et al. Vascular dementia: diagnostic criteria for research studies. Report of the NINDS-AIREN International Workshop. Neurology 1993:43:250-60.
3 Knopman DS, Parisi JE, Boeve BF, et al. Vascular dementia in a population-based autopsy study. Arch Neurol 2003:60:569-75.

4 Chui HC, Mack W, Jackson JE, et al. Clinical criteria for the diagnosis of vascular dementia: a multicenter study of comparability and interrater reliability [see comments]. Archives of Neurology 2000;57:191-6.

5 Looi J, Sachdev P. Differentiation of vascular dementia from $A D$ on neuropsychological tests. Neurology 1999;53:670-8.

\section{Depressive symptoms and cognitive decline-disentangling the effect of affect}

\section{R Stewart}

\section{Time to take depression seriously?}

s depression a risk factor for cognitive decline? Dementia, a potential consequence of cognitive decline, is a devastating disorder. If depression is a risk factor, it is important because it is common. Therefore, even a weak riskoutcome association might represent a substantial population level impact and "account for" a large number of dementia cases. It is not surprising that a growing body of observational research has sought to address this question, including the analysis by Wilson et al in this issue (pp 126-9). ${ }^{1}$ However, unfortunately we are still a long way from establishing causation and measurements of exposure leave a lot to be desired.

Several prospective studies have shown that depressive symptoms are associated with an increased risk of developing dementia. ${ }^{2}$ It is possible that depression may actually initiate or accelerate neurodegenerative processes. This is obviously of particular interest given the implied possibility of preventing cognitive decline and dementia. However, there are other potential explanations. Depression may simply be a reaction to a perceived deterioration in cognitive function. Alternatively, cognitive function may be impaired during a depressive episode because of reduced attention and motivation, so that someone may present with apparent clinical dementia at a relatively early stage of neurodegeneration. These two explanations are addressed in the analysis carried out by Wilson et al and are not supported by their findings because increased baseline depressive symptoms predicted cognitive decline independently of baseline cognitive function. A third explanation is that depression is a prodromal symptom of dementia rather than a risk factor. This hypothesis is less easy to test. It would predict a greater level of neurodegenerative pathology associated with depressive symptoms in people without clinical dementia in life. However, population based pathological data are hard to come by. Wilson et al cite a report in press at the time of submission $^{3}$ which may shed light on this issue but further research is likely to be required.

So where to go from here? A disappointing feature of most research in this area has been the simplistic approach to depression as an exposure. Some studies focus on categories such as major depression, which poorly characterise late life affective disorder. ${ }^{4}$ Most, including that by Wilson et al, do not investigate depression but depressive symptoms. But can a person's mood state be adequately reflected by summing up a short list of symptoms? What about the pervasiveness of individual symptoms themselves, their nature (such as the type of sleep disturbance) or underlying clustering (for example, motivation and affect)? Levels of affective disturbance fluctuate throughout the life course and are likely to have complex, interdependent relations with other aspects of health, such as cognitive function and somatic states (for example, vascular disease). ${ }^{5}$ Secondary analyses of high quality longitudinal datasets have undoubtedly made substantial contributions to this research field, but are invariably limited by measurements that have to cover a large number of objectives. Dysphoric symptoms predict a wide variety of adverse outcomes but are rarely measured in any detail. Perhaps it is time to take depression seriously.

J Neurol Neurosurg Psychiatry 2004;75:5. doi: 10.1136/jnnp.2003.028399

\section{Author's affiliation}

R Stewart, Institute of Psychiatry, Denmark Hill, London SE5 8AF, UK; r.stewart@iop.kcl.ac.uk

\section{REFERENCES}

1 Wilson RS, Mendes de Leon CF, Bennett DA, et al. Depressive symptoms and cognitive decline in a community population of older persons. J Neurol Neurosurg Psychiatry 2004:75:126-9.

2 Geerlings MI, Schoevers RA, Beekman ATF, et al. Depression and risk of cognitive decline and Alzheimer's disease. Results of two prospective community-based studies in the Netherlands. Br J Psychiatry 2000 176:568-75.

3 Wilson RS, Schneider JA, Bienias JL, et al. Depressive symptoms, clinical AD, and cortical plaques and tangles in older persons. Neurology (in press).

4 Snowdon J. Epidemiologic questions on mood disorders in old age. Clin Neurosci 1997;4:3-7.

5 Stewart $R$. The interface between cerebrovascular disease, dementia and depression. In: Chiu E, Ames D, Katona C, eds. Vascular disease and affective disorders. London: Martin Dunitz, 2002. 